\title{
Reviewing Gender Discrimination in K12 Education
}

\author{
Zhuofei $\mathrm{Lv}^{1, *}$ \\ ${ }^{1}$ School of Foreign Language, Shanghai Maritime University, Pudong Area, Shanghai, 201306, China \\ "Corresponding author. Email: zhuofei.lv@Vanderbilt.edu.
}

\begin{abstract}
This paper reviews five main manifestations and causes of gender discrimination in K12 education: teaching materials, teachers' attitudes, educational opportunities, traditional family concepts, and family investments in education. By analyzing these factors, the researcher tries to find out the appropriate ways to alleviate gender discrimination, which aims to promote gender equality in education. The researcher analyzed these factors by using the literature review method. The researcher mainly finds that: 1) K12 textbooks show gender discrimination through illustrations and contents; 2) In K12 education, teachers' unbalanced care and stereotypes towards male and female students also lead to gender discrimination in classes; 3) The idea of son preference and discrimination against women in the workplace will push families to become more inclined to provide men with more educational resources. This paper is helpful for teachers, students, and parents to realize gender equality in K12 education, which might inspire them to treat girls more equally in education.
\end{abstract}

Keywords: Gender discrimination, K12 education, Textbook, School, Family.

\section{INTRODUCTION}

Gender discrimination occurs in K12 education, which is shown in the teaching process and family supports. But it should be avoided to improve teaching quality and let students form the idea of gender equality. This review paper is to investigate two research questions. The first one is what are the main manifestations and causes of gender discrimination in K12 education. The second one is how to alleviate this problem. This review covers two aspects leading to gender discrimination: school level and family level. This paper will review the two levels in detail in the main body part.

\section{SCHOOL LEVEL}

Jane Roland Martin, a philosopher of education, believes that there are two extremes in western education, either completely ignoring gender or only considering gender, which has brought serious harm and inequality to males and females, especially female students [1]. To avoid such harm and inequality, the alternative is to maintain the sensitivity of gender awareness in education [1]. In China, lots of schools also try to achieve gender equality by unifying it neutrally. For example, female and male students should all wear the same uniform in school, and they have the same textbooks. However, this kind of gender neutrality ignores the natural gender differences between male and female students in the biological sense.
It ignores the cultural gender differences in the sociological sense in the process of students' individual growth. As a result, Ding and Yue claim that the process of pursuing educational equality has become a process of artificially creating gender discrimination in education [2]. However, this paper argues that gender neutrality in education will blur gender differences and have a negative impact on the formation of students' gender consciousness. But the way of treating male and female students equally does not lead to gender discrimination. Therefore, there is a certain degree of gender bias in current K12 education, whether in practice or the policy. There is sexism in educational opportunities, educational content, textbook compilation, teachers' attitude, students' subject choices, etc.

\subsection{Teaching Materials}

The construction of teaching materials is an important part of the whole education work [3]. If there is gender discrimination in textbooks, it will have a negative impact on students' cognitive development. But in the teaching materials of K12 education, sometimes there are some contents containing gender stereotypes or discrimination, which will lead to wrong guidance for the formation of students' gender consciousness. Therefore, it is extremely important to 
eliminate the phenomenon of gender discrimination in the teaching materials.

\subsubsection{Illustration}

The illustration is one of the most important parts of textbooks. Most of the students in K12 education mainly think in their cognitions with images. Hence, illustration has a certain impact on students' cognition of men and women. In many textbooks, there are gender discriminations in illustrations related to gender characteristics. That is, men are the most important, and women are the least important.

In foreign English textbooks, there are gender differences, and gender discriminations in the illustrations of textbooks, which manifests in those men are superior to women. Gender discrimination in illustrations of foreign English textbooks is mainly reflected in men and women's frequency of occurrence and social status [4]. Hartman and Judd surveyed several textbooks to prove that women are limited to stereotyped roles such as housework and childcare [5]. In terms of housework, women tend to cook, wash cloths, and so on, while men are engaged in car repair, light bulb replacement, lawn mowing, and other activities. However, some studies have found that the phenomenon of male dominance is changing to the trend of equality between men and women. For example, Yusuf and Mustafa found that in most cases, there is no sign of gender inequality in the ELT (English Language Teaching) coursebook series Yes You Can [6]. This paper would argue that more and more people have noticed gender discrimination in education. Therefore, this phenomenon has been improved, which is a good thing. However, the role of males and females is flexible. Thus, the traditional gender stereotypes should also be avoided in teaching materials.

In China, based on the research results of domestic scholars, there is a common gender difference phenomenon in the illustration of various versions of textbooks in primary and secondary schools: the choice of textbook figure illustration tends to be "son preference." Zheng analyzed the gender issues in high school physical education textbooks and concluded that there was gender bias in the illustrations and contents of the textbooks. Wang studied the gender issues in middle schools ideological and moral education textbooks from the two aspects of textbook illustrations and content and concluded that male illustrations are significantly more than female, and the text content tends to praise men. The number of male characters is far more than that of female characters. Male characters tend to be more confident, tall, and powerful; on the contrary, female characters are emotional and self-abased [7]. Students in K12 education prefer illustrations in books to words. The information implied by illustrations is quite important. Therefore, the illustrations in textbooks should convey the concept of gender equality to students, or female students may be self-abased under the influence of gender stereotypes. For example, the illustration can be a woman who performs well at work.

\subsubsection{The Character Settings in the Text}

In textbooks, both men and women have a certain degree of stereotypical positioning from identity to temperament. Men are usually the image of leadership, while women are the image of being led, and men make more money than women. Additionally, in the Chinese teaching materials of the elementary education stage, there are always many ancient poems about those men do farm work and women engage in spinning and weaving, advocating that "men dominate the outside and women dominate the inside". There is also the idea that only men can go to school. In 1988, Yau studied Chinese history and social science textbooks for junior high school students [8]. They studied the two series of textbooks from the perspectives of gender roles, division of labor, etc. The results show that the two sets of textbooks still have the problem of stereotypes in depicting the gender roles of men and women. Most of the places where mothers live outdoors are markets or supermarkets. Mothers are mainly responsible for taking care of their children's daily life and health, such as accompanying their children to school and seeing doctors. Long studied the primary school Chinese textbooks published by the people's education press in 2003 and found that the distribution of roles in the textbooks is uneven. Most of the textbooks depict women as docile, family-oriented, and male-centered images while ignoring the outstanding performance of women in the workplace [9]. Therefore, to avoid conveying this inappropriate gender concept to students, textbook compilers should consciously try to balance the gender occurrence frequency of men and women.

To avoid conveying the idea of gender discrimination to students, teachers should also actively guide them and tell them that these ideas of gender stereotypes have changed in modern times, in which men and women can freely choose what to do. Meanwhile, textbook compilers should not always strengthen men and weaken women but should convey the concept of equality between men and women to students.

\subsection{Teachers' attitude}

Chen conducted a random sampling survey on the gender awareness of rural primary and secondary school teachers in Qianshan County, Jiangxi Province. The results show that: (1) the concept of gender equality of teachers is not mature; (2) teachers have a strong sense of female family role; (3) teachers' concept of female development is deeply influenced by traditional gender concept; (4) the gender attitude of teachers is unfair, and 
there are gender stereotypes. Therefore, during the process of teaching, teachers may have gender discriminations, which should be avoided.

In K12 education, teachers are always willing to ask questions to boys because they think boys are braver than girls to speak in public. In this case, boys can engage in classes better than girls. Therefore, teachers should pay more attention to female students' psychology, help them build confidence, and encourage them to participate in classroom activities.

However, there are also gender stereotypes of boys. In the real educational environment, teachers have higher requirements for boys. They wish that boys can master more skills and better protect their families and the country. But many boys cannot bear so much pressure and often feel frustrated. Therefore, in K12 education, this phenomenon should also be changed. Teachers should not generally think about what boys and girls should be like because of their gender, but should find out the potential of each student, teach students in accordance with their aptitudes, and find suitable education methods for them.

\subsection{Educational opportunities}

In China, because of the compulsory education law, males and females have equal rights to go to school in the K-12 period. And in America, on December 10, 2015, Obama signed the "Every Student Successes Act" to replace the "No Child Left Behind" act, which has been in force for more than 10 years. The aim is to improve the quality of K-12 education in the United States. It is precisely because of the promulgation and implementation of these laws that the right of men and women to education tends to be equal at present. That is, they all have access to K-12 education.

But according to Geng, the proportion of women receiving higher education is gradually decreasing with the improvement of education level [10]. The higher the education level, the fewer women, the greater the gender difference between men and women.

This paper argues that while ensuring equal access to basic education for men and women, women with high academic and professional levels can be encouraged to receive higher education instead of accepting the idea that women should attach importance to family.

\section{FAMILY LEVEL}

\subsection{Traditional Family Concept}

According to the traditional idea in China, only men can receive education, and when there are several kids in a family, girls should take care of boys. Better and more precious resources need to be given to the boys at home. As Chinese families have limited education resources at that time, parents only gave education opportunities to boys, and girls need to make money to subsidize their families. But now, people are still used to accepting this idea of son preference. The idea of "son preference" is the product of private ownership and patriarchy. It has been promoted unremittingly in the feudal society for thousands of years and has become a typical backward culture. However, although the current level of product development in China is improving, and it is also in the upsurge of promoting advanced culture, the phenomenon of "son preference" still exists in many rural areas [11]. From my perspective, "son preference" is the inheritance of dross culture. At the same time, because society recognizes the dominant position of men, families also tend to attach importance to men and ignore women. Therefore, sometimes parents still tend to give more educational resources to sons than daughters. In the traditional family concept, parents wish that boys can have adventure spirits and have chances to see the outside world. Still, they think girls better stay with them because of the traditional family concept. However, females also have the right to receive higher education and improve their own abilities, and they should choose the life they want, but not listen to parents.

In addition, impoverished people always believe that girls do not need to have a high degree because of farming culture. If girls have a good personality with a beautiful appearance, they can live a good life by getting married. Therefore, most parents will not give girls more educational resources.

From my perspective as a female, the most secure life is still given by myself, and I am willing to improve my ability rather than rely on men. In this new era of social development, women should be independent. I hope each family can accept this new idea and balance the resources given to boys and girls.

\subsection{Family Investments in Education for Boys and Girls}

The results of Wu's paper show that there is gender inequality in China's labor market, and there is a trend of expansion compared with other countries [12]. Females are more vulnerable to discrimination in the process of employment. In this case, Becker's neoclassical family model points out that parents have an optimal level of education investment for each child in the process of family-based optimization. The net present value of the expected benefits of Education tries to become equal to the education cost of the family. Due to gender discrimination in the labor market, many Chinese families will inevitably invest more resources in boys' education.

Therefore, to solve the imbalance problem of family investment in education between men and women, it is necessary to alleviate the discrimination against women 
in the job market. First, it is necessary to formulate relative laws and regulations to protect women's rights, thereby building a relaxed employment environment for women and eliminating gender discrimination in the employment field. Secondly, most of the gender discrimination of women in employment is due to women's responsibility of nurturing and taking care of kids. Then it is important to improve the antidiscrimination approaches for females. For example, they can make complaints whenever they encounter discrimination. Society should expand employment opportunities for women through multiple channels, promote gender equality, and eliminate people's traditional concept of son preference.

Cai, Meng, and Ma found that the higher the level of education for parents, the smaller the gender gap of children's access to education, and the influence of mothers on the gender inequality of access to education is greater than that of fathers [13]. At the same time, family size also influences gender inequality seriously. the more brothers and sisters there are, the more serious the gender inequality in access to education is. Therefore, parents should consider the number of children according to their own economic conditions to prevent the unequal distributions of educational resources. At the same time, in the case of many children, parents should try to balance the allocation of resources and abandon the idea of son preference.

Meanwhile, females should be popularized with relevant legal knowledge, and when they are deprived of the right to education, they should know how to protect their rights.

The Political Bureau of the CPC (Communist Party of China) Central Committee held a meeting on May 31. The meeting pointed out that the fertility policy should be further optimized, implementing the policy of one couple having three children. Under the influence of this policy, there possibly will be more kids in a family, which may make the distribution of educational resources more unequal. Additionally, this policy may increase the pressure on women's lives and the economy so that they have less time for further studies, leading to gender inequality and possible serious gender discrimination in the workplace.

\section{CONCLUSION}

In this review, the researcher analysed some main causes of gender discrimination in K12 education from two aspects: school and family level. The researcher also points out some useful suggestions to improve this phenomenon. From the school level, both sexist content and illustration in teaching materials and teachers' different attitudes towards male and female students can lead to gender discrimination in K12 education. From the family level, parents may provide their sons more educational resources than daughters because of the traditional concept and the unbalanced treatment in the job market. Based on the research, the main findings are as follows:1) K12 textbooks show gender discrimination through illustrations and contents, in which the number of male roles is larger than females. Also, males are brave and confident to show leadership while females are only supporting roles; 2) In K12 education, teachers' unbalanced care and stereotypes towards male and female students also lead to gender discrimination in school. 3) When it comes to higher education levels, there are fewer women than men with large gender gaps; 4) The idea of son preference and discrimination against women in the workplace will make families more inclined to provide men with more educational resources.

By reading this review article, textbook compilers and teachers can have the consciousness to avoid gender discrimination in K12 education. In addition, parents may pay more attention to their daughters' education. During the period of K12 education, male and female students will construct their gender consciousness. Thus, it is important to convey correct gender values and gender equality to them in $\mathrm{K} 12$ education.

\section{REFERENCES}

[1] Zhou X. L., \& Du S. Z. (2008). Educational tradition and its transcendence from the perspective of gender. Educational research (10),33-38. DOI: CNKI: SUN: JYYJ.0.2008-10-006.

[2] Ding G., \& Yue L. (2004). Educational equality in school environment--Investigation and Reflection on the gender weakness of male students in basic education. Education in China: research and review, $6(1), 1-70$.

[3] Yu G. (1996). Pay attention to the construction of teaching materials. Seeking Truth (22),35. DOI: CNKI: SUN: QUSI.0.1996-22-016.

[4] Fang Y. (2020). Research on gender representation of illustrations in foreign English textbooks. English Square (20),51-53. DOI: 10.16723/j.cnki.yygc.2020.20.016.

[5] Bahman, M. (2017). Iranian High Schools: Occupational Visibility in English Textbooks.

[6] Demira Y. M. (2017). Do ELT coursebooks still suffer from gender inequalities? a case study from turkey. Journal of Language \& Linguistic Studies, 13.

[7] Zhu X. B. (1994). On the socialization of children's gender role from three primary school Chinese Textbooks in China-A comparison with an American reading textbook. Education Research (10),52-57. doi:CNKI:SUN:JYYJ.0.1994-10-010. 
[8] Yau, L. L. (1988). Equal opportunity commission of Hong Kong, 2001:57-72

[9] Long J.(2012). Analysis of gender role in primary school Chinese textbooks (Master's thesis), Hunan Teachers' University.

[10] Geng H. L. (2016). Gender discrimination in China's Higher Education. The editorial department of Science and Technology and Enterprise. (eds.) "Decision Making Forum-Symposium on the application and analysis of management decision making" (Part 2) (pp.109).

[11] Gao C.(2019). On the idea of son preference in All is Well. Home of drama (20),97+99. DOI: CNKI: SUN: XJZT.0.2019-20-066.

[12] Wu Z. Z. (2008). Comparison of gender inequality in labor market between China and foreign countries under the background of transformation. The Economist (02),116-121. DOI: CNKI: SUN: JJXJ.0.2008-02-019.

[13] Cai D. L., Meng X. Y., \& Ma S. (2016). Family background and gender inequality in educational attainment. Financial Science (10),110-120. DOI: CNKI: SUN: CJKX.0.2016-10-011. 